\title{
Science at a distance: the CHESS experience
}

\section{Szebenyi ${ }^{1}$, R Gillilan ${ }^{1}$, A Finke ${ }^{2}$ \\ ${ }^{1}$ MacCHESS, Cornell Univ, Ithaca, NY, ${ }^{2}$ Cornell University, Groton, NY dms35@cornell.edu}

MacCHESS has supported remote operation at a macromolecular crystallography (MX) station, and mail-in operation at a BioSAXS station, at CHESS (the Cornell High Energy Synchrotron Source) for years. Now, restrictions due to COVID-19 have required rethinking of modes of operation, not only for MX and BioSAXS, but for all stations at CHESS. This poster reports on developments made for operation in June 2020, and those planned for the October 2020 run. Critical factors for successful experiments include: • Recognition that setup time may be longer than under previous conditions - Use of multiple communication modes - Detailed scheduling of activities, coordinating with other stations - Contingency planning in case of equipment failure or personnel non-availability We anticipate that remote and mail-in modes of operation will be available for most experiments at every station, saving on travel expenses as well as allowing convenient collaboration between multiple experimenters.

Acta Cryst. (2020). A76, a210 